\title{
Study on Farmland Demarcation Based on County Land Management Quality Zoning
}

\author{
A Case Study on Cha County
}

\author{
Xiangdong Cao \\ Xinjiang Education Institute \\ Urumchi, Xinjiang 830046
}

\author{
Xinjuan Shao \\ Xinjiang Education Institute \\ Urumchi, Xinjiang 830046 \\ Xiuhua Li \\ Xinjiang Education Institute \\ Urumchi, Xinjiang 830046
}

\author{
Huali Fan \\ Xinjiang Education Institute \\ Urumchi, Xinjiang 830046 \\ Yan Wang \\ Xinjiang Education Institute \\ Urumchi, Xinjiang 830046
}

\begin{abstract}
The quality zoning of land management reflects the management level of regional agricultural production and is also the basis of demarcation of basic farmland reserve. This paper chooses QapqalXibe Autonomous County in Yili River Valley as a research area to construct a comprehensive evaluation index system of cultivated land quality in QapqalXibe Autonomous County using methods such as exponential decay assignment, multi - factor comprehensive evaluation and multi factor index based on four index factors, namely land natural quality, cultivated land use condition, land spatial form and ecological security pattern, and determine the land management quality zoning plan of the research area according to the quality evaluation level of each index. The results show that the land quality in the research area is generally in good condition, and $55.74 \%$ of the county's cultivated land is of relative high quality, and $44.99 \%$ of the cultivated land is demarcated as the basic farmland priority reserve, and the land management quality zoning of the research area plays a good role.
\end{abstract}

Keywords-cultivated land quality; comprehensive evaluation; basic farmland demarcation

\section{INTRODUCTION}

Good land management is the basis of agricultural production, is the fundamental guarantee for food security and social stability, and with the rapid development of today's economic society, higher requirements for land management is put forward [1-2]. Land management related issues are also discussed in recent years, and in the perspective of management, many domestic scholars carried out a large number of studies in terms of cultivated land quality assessment, high standard basic farmland demarcation scheme, basic farmland reserve exploration or model optimization layout, etc. [9-11] by using the multi-factor comprehensive evaluation method, AHP model, PSR model, LESA method and so on [5-8]based on the indexes such as land natural features, location advantages, site base and policy measures, etc.[3-4], which improves the research system for basic farmland. However, the study on ecological security pattern lacks a relatively precise example.

\section{OVERVIEW AND DATA PROCESSING OF THE RESEARCH AREA}

\section{A. Overview of the Research Area}

QapqalXibe Autonomous County (hereinafter referred to as "Cha County") is located at the northern foot of the Western Tianshan Branch Wusun Mountain in the vast valley basin south of the Ili River in Xinjiang. The terrain is narrow in the east and wide in the west, and high in the south and low in the north, which leans from southeast to northwest, and its geographical location is within $80^{\circ} 30^{\prime} 00^{\prime \prime} \sim 81^{\circ} 45^{\prime} 00^{\prime \prime} \mathrm{E}$ and $43^{\circ} 15^{\prime} 00^{\prime \prime} \sim 43^{\circ} 57^{\prime} 30^{\prime \prime} \mathrm{N}$. The total land area of the county is $364,041.95 \mathrm{hm} 2$ (excluding corps area), which has jurisdiction over 2 towns, 11 townships, 6 fields and 1 military sub-district. At the end of 2013, there were 167,300 permanent residents in the county, of which 111,600 were registered agricultural population with the GDP up to RMB 3.989 billion yuan and total local financial revenue of RMB 999 million yuan. According to the database of land use change, the cultivated area of the county is $84,948.67 \mathrm{hm} 2$, accounting for $23.33 \%$ of the total land area of the county. As an important agricultural county and a demonstration area for the land remediation of the main canal of south bank of Yili River Valley, one of the hot spots in the current work of Cha County is the demarcation of basic farmland. Therefore, the research area is selected as the target area for discussion. 


\section{B. Data Processing}

The land involved in this paper is studied for the quality level of cultivated land. The data used in the study were mainly derived from the 1:100,000 present land-use map, the data of Digital Elevation Model (DEM) and the map of agricultural land gradation, etc. of Cha County.

\section{ANALYSIS OF RESEARCH AREA}

\section{A. Comprehensive Evaluation Index System of Cultivated Land Quality}

1) Evaluation of the natural quality of cultivated land

The natural quality of cultivated land is the foundation of agricultural production, and the high quality cultivated land can be used as the priority area of basic farmland. The quality of cultivated land can be objectively reflected under the comprehensive influence of soil texture, soil fertility and irrigation and drainage facilities and other factors [12]. Therefore, this study selects the percentage system combined with the multi-factor comprehensive evaluation method and the expert scoring method to determine the main indexes and weights of evaluation of the natural quality of cultivated land (see "Table I" for details), and calculate the natural quality of cultivated land in the research area to provide basis for the demarcation of basic farmland in Cha County. The calculation formula is as follows:

$$
R_{i j}=\sum_{r=1}^{m \times n} g_{(i j)} \times C_{r}
$$

TABLE I. Evaluation SyStem OF NATURAL QuAlity OF CUltivated LAND AND ITS WEIGHTS

\begin{tabular}{|c|c|c|c|c|c|c|c|c|c|}
\hline $\begin{array}{l}\text { Index } \\
\end{array}$ & Weight & 100 & 90 & 80 & 70 & 60 & 50 & 40 & 10 \\
\hline $\begin{array}{c}\text { Thickness of Effective Soil } \\
\text { Layer }(\mathrm{Cm})\end{array}$ & 0.250 & Unlimited & $\geq 100$ & & $60-100$ & & & $30-60$ & $<30$ \\
\hline Topsoil Texture & 0.222 & Loam & Clay & & $\begin{array}{l}\text { Sandy } \\
\text { soil }\end{array}$ & & & Gravel soil & \\
\hline $\begin{array}{l}\text { Mass Fraction of Soil } \\
\text { Organic Matter (\%) }\end{array}$ & 0.194 & 4.0 & $3.0-4.0$ & & $1.0-2.0$ & $0.6-1.0$ & $<0.6$ & & \\
\hline Probability of Irrigation & 0.333 & $\begin{array}{l}\text { Fully } \\
\text { satisfied }\end{array}$ & & $\begin{array}{l}\text { Basically } \\
\text { satisfied }\end{array}$ & & $\begin{array}{l}\text { Generally } \\
\text { satisfied }\end{array}$ & & $\begin{array}{l}\text { No irrigation } \\
\text { condition }\end{array}$ & \\
\hline
\end{tabular}

In the formula, Rij is the total score of the natural quality of the cultivated land of the ij grid. G (ij) $r$ is the score of the $r$ factor in the ij grid; $\mathrm{Cr}$ is the relative weight of the $\mathrm{r}$ factor.

\section{2) Evaluation of cultivated land use benefit}

The advantages and disadvantages of the utilization condition of cultivated land can reflect the utilization quality of cultivated land to some extent, and the advantageous location conditions and farming environment can improve the agricultural production efficiency. Therefore, this study selected four indexes, namely the influence degree of agricultural trade center, road accessibility, cultivation distance and cultivation convenience, to comprehensively evaluate the advantages and disadvantages of the utilization conditions of cultivated land. This paper selects different levels of towns as the agricultural trade influence center and calculates their location distances to the farmland plots, which was used to reflect the influence degree of the agricultural trade center on the utilization of cultivated land, and calculates the minimum distance of rural residents as the cultivation distance, and select the main roads and rural roads in Cha County to calculate the road accessibility and cultivation convenience of the cultivated land respectively.

\section{3) Evaluation of cultivated land spatial form}

The spatial continuity of cultivated land is not only conducive to improving agricultural production level, but also helps to avoid the fragmentation of cultivated land caused by urban sprawl, in this study, we selects two indexes of plot regularity and continuity to describe the continuity of cultivated land; The regular plot shape is conducive to improving the mechanization of the field and increasing agricultural productivity. In this study, the plot fractional dimension in the landscape ecology is selected to describe the plot regularity, and the smaller the general index is, the higher the degree of regularity is.

4) Evaluation of the ecological security pattern of cultivated land

The evaluation of the ecological security pattern of cultivated land mainly reflects the ecological security degree of cultivated land production. In general, the more stable the regional ecological system is and the lower the ecological risk is, the greater the possibility that the farmers will settle and cultivate.

\section{B. Comprehensive Evaluation of Cultivated Land Quality}

In this study, the multi-factor index method [1] was adopted to apply ArcGIS software to overlay the various criterion layers of the evaluation of cultivated land quality to calculate the comprehensive evaluation score of each evaluation unit of cultivated land:

$$
A Q=\sqrt[n]{\prod_{m=1}^{n} Y_{m}}
$$

In the formula, AQ is the score of cultivated land quality, and $\mathrm{Ym}$ is the quality score of the $\mathrm{m}$ criterion layer. 


\section{RESUlT AND ANALYSIS}

\section{A. Evaluation Index Quantification of Cultivated Land Quality}

We shall calculate the quality evaluation score of each criterion layer through the calculation formula of each evaluation index. The evaluation score of natural quality of the cultivated land in Cha County which is calculated through the comprehensive index analysis method, is from 51.76 to 97.96 , which states the natural quality of land in Cha County is relatively high. The evaluation score of utilization condition of cultivated land in Cha County which is calculated through the attenuation assignment method, is from 36.78 to 96.02 . The evaluation score of spatial form of cultivated land in Cha County shall be determined according to the plot continuity, regularity and weighting assignment. In consideration of the slope, vegetation coverage and land use type, we shall use the comprehensive index evaluation method to calculate the evaluation score of ecological security pattern in Cha County.

\section{B. Comprehensive Evaluation Result of Cultivated Land Quality}

Through the superposition calculation of multiple-factor index method, the comprehensive evaluation result of cultivated land quality in Cha County is from 36.63 to 85.63. And the lands are divided into the highest quality area, the higher quality area, the medium quality area, the lower quality area and the poor quality area. The proportion of cultivated land area of each type is respectively $20.72 \%, 35.02 \%, 25.12 \%$, $13.52 \%$ and $5.63 \%$ ("Table II"). It can be seen that most of the cultivated land in Cha County is located in the high quality area, which is suitable for the demarcation of basic farmland. And the cultivated land is mainly located in north of Cha County (including Sun ZhaqiNiu Lu Xiang, Dui YiqiNiu Lu Xiang and AixinsheliTown ).

TABLE II. QUality Classification OF CULTIVATED LAND IN EACH VILLAGE AND TOWN

\begin{tabular}{|c|c|c|c|c|c|c|c|c|c|c|}
\hline \multirow[t]{2}{*}{$\begin{array}{l}\text { Villages And Towns } \\
\text { (Unit) }\end{array}$} & \multicolumn{2}{|c|}{ Poor Quality Area } & \multicolumn{2}{|c|}{ Lower Quality Area } & \multicolumn{2}{|c|}{$\begin{array}{c}\text { Lower Quality } \\
\text { Area }\end{array}$} & \multicolumn{2}{|c|}{ High Quality Area } & \multicolumn{2}{|c|}{ Highest Quality Area } \\
\hline & $\begin{array}{l}\text { Area } \\
(\mathrm{Hm} 2)\end{array}$ & $\begin{array}{l}\text { Proporti } \\
\text { on (\%) }\end{array}$ & $\begin{array}{l}\text { Area } \\
(\mathrm{Hm} 2)\end{array}$ & $\begin{array}{l}\text { Proportion } \\
(\%)\end{array}$ & Area & \begin{tabular}{|c|}
$\begin{array}{c}\text { Proportion } \\
(\%)\end{array}$ \\
\end{tabular} & Area & $\begin{array}{c}\text { Proportion } \\
\text { (\%) }\end{array}$ & Area & $\begin{array}{l}\text { Proportion } \\
(\%)\end{array}$ \\
\hline $\begin{array}{c}\text { Anbanbage Feeding } \\
\text { Farm }\end{array}$ & 4.97 & 0.10 & 24.88 & 0.22 & 27.81 & 0.13 & 260.87 & 0.88 & 358.24 & 2.04 \\
\hline Na Daqiniu Lu Xiang & 11.76 & 0.25 & 98.93 & 0.86 & 422.18 & 1.98 & 1337.16 & 4.49 & 1285.36 & 7.30 \\
\hline Chabucha'erTown & 12.08 & 0.25 & 123.43 & 1.08 & 820.51 & 3.85 & 1518.90 & 5.11 & 702.30 & 3.99 \\
\hline Tuobo Breeding & 82.56 & 1.73 & 528.42 & 4.60 & 1905.05 & 8.93 & 2724.14 & 9.16 & 2004.90 & 11.39 \\
\hline Sun Zhaqiniu Lu iang & 6.84 & 0.14 & 281.67 & 2.45 & 1646.72 & 7.72 & 4800.53 & 16.14 & 2373.06 & 13.48 \\
\hline Dui Yiqiniu Lu Xiang & 61.64 & 1.29 & 296.84 & 2.59 & 1159.18 & 5.43 & 2606.85 & 8.76 & 3013.94 & 17.13 \\
\hline Aixinsheli Town & 131.85 & 2.76 & 624.89 & 5.44 & 1733.70 & 8.12 & 2384.09 & 8.01 & 2139.11 & 12.16 \\
\hline Chuohuoer Township & 182.72 & 3.82 & 566.38 & 4.93 & 976.22 & 4.57 & 1298.69 & 4.37 & 622.61 & 3.54 \\
\hline Zakuqiniu Lu Xiang & 19.58 & 0.41 & 449.65 & 3.92 & 1571.31 & 7.36 & 2807.71 & 9.44 & 1872.29 & 10.64 \\
\hline $\begin{array}{l}\text { Mi Liang Quanhuizu } \\
\text { Xiang }\end{array}$ & 15.71 & 0.33 & 109.50 & 0.95 & 679.45 & 3.18 & 740.63 & 2.49 & 257.98 & 1.47 \\
\hline Qiong Bo Le Xiang & 299.53 & 6.27 & 599.71 & 5.22 & 1248.02 & 5.85 & 1156.14 & 3.89 & 241.16 & 1.37 \\
\hline Giagesitai Township & 1394.46 & 29.17 & 3007.46 & 26.20 & 1854.85 & 8.69 & 497.53 & 1.67 & 283.90 & 1.61 \\
\hline Hainuke Township & 363.97 & 7.61 & 1523.64 & 13.27 & 3058.91 & 14.33 & 3191.95 & 10.73 & 722.35 & 4.10 \\
\hline Kuohongqi Township & 1577.38 & 33.00 & 1424.46 & 12.41 & 994.19 & 4.66 & 1592.47 & 5.35 & 1024.06 & 5.82 \\
\hline Kan Town & 510.08 & 10.67 & 1372.26 & 11.95 & 1797.94 & 8.43 & 1470.10 & 4.94 & 317.67 & 1.81 \\
\hline $\begin{array}{c}\text { Direct Land of } \\
\text { Qapqalxibe } \\
\text { Autonomous County }\end{array}$ & 8.55 & 0.18 & 59.49 & 0.52 & 58.83 & 0.28 & 66.90 & 0.22 & 4.81 & 0.03 \\
\hline Dairy Farm & 90.47 & 1.89 & 343.25 & 2.99 & 1262.94 & 5.92 & 1211.23 & 4.07 & 309.04 & 1.76 \\
\hline Chicken House & 0.67 & 0.01 & 5.67 & 0.05 & 10.29 & 0.05 & 23.49 & 0.08 & 31.78 & 0.18 \\
\hline Plain Forest Farm & 0.58 & 0.01 & 0.29 & 0.00 & 57.17 & 0.27 & 55.70 & 0.19 & 33.21 & 0.19 \\
\hline Military Subarea & 4.32 & 0.09 & 40.07 & 0.35 & 54.31 & 0.25 & 5.66 & 0.02 & 0.00 & 0.00 \\
\hline Total & 4779.72 & 100 & 11480.88 & 100 & 21339.58 & 100 & 29750.72 & 100 & 17597.76 & 100 \\
\hline
\end{tabular}




\section{Demarcation Analysis of Basic Farmland}

In order to ensure that the conditions, such as farming base, production location and continuity of the selected cultivated land, are sufficient to meet the requirements of contiguous high quality cultivated land of the basic farmland delimitation, the preliminary analysis of basic farmland delimitation for the cultivated land in Cha County shall be carried out according to the comprehensive evaluation result of cultivated land quality, and the specific score of each evaluation index. First, by the natural breakpoint method, the value of each criterion layer index shall be divided from high to low: Grade I, Grade II and Grade III. Then the farmland in Cha County shall be divided according to comprehensive quality score level, so as to determine the priority area, regulation and adjustment area, regulation and reserve area, and farmland regulation area.

\section{1) Priority area}

In the highest quality area, the cultivated land's natural quality, land use efficiency, spatial connectivity, and the ecological security pattern are at a high level. As a priority area, it is directly included in the basic farmland protection area of Cha County. The cultivated land of high quality area shall be selected and the index value of each standard layer is in the rank area of Grade I and II. From the view of villages and towns, it is mainly located in the towns such as Sun ZhaqiNiu Lu Xiang,Dui YiqiNiu Lu Xiang and ZaKuqiNiu Lu Xiang.

\section{2) Regulation and adjustment area}

The cultivated land in the remaining high quality area shall be incorporated into the regulation and adjustment area, and most of these areas need to be improved in response to some of the factors. With its own relatively high comprehensive quality score, it can be delimited into the basic farmland protection area through regulation and optimization. Considering that cultivated land has a strong natural restriction on ecological safety and natural quality, it is not easy to renovate and change by labor. Therefore, the ecological safety and natural quality in the middle quality area are located in the areas of Grade I and II. the ecological safety and natural quality in the lower quality area are located in the area of Grade I as the regulation and adjustment area. The cultivated land in these areas has a good cultivability. As long as the spatial form of the land is properly regulated and the convenience of traffic is improved, the cultivated land can be delimited into the basic farmland protection area. From the point of view, in the remediation area is mainly distributed Lu Xiang, tobo sheep farm in sun Zazi cattle town. From the view of villages and towns, the regulation and adjustment area is mainly located in the towns such as Sun ZhaqiNiu Lu Xiang and Tuobo Breeding Sheep Farm.

\section{3) Regulation and reserve area}

The value of each index in the remaining medium quality area and the lower quality area is located in the areas of Grade I and II, and the value of each index in the poor quality area is located in the area of Grade I that is divided into the regulation and reserve area. The overall integrated value of cultivated land in these areas is relatively low, but the difference of partial index scores is large, which needs to be sorted out pertinently. It can be considered that the plots with some good index but a low overall comprehensive value shall be also delimited into the basic farmland protection area. From the view of villages and towns, the regulation and reserve area is mainly located in the towns such as Hainuke Township and Giagesitai Township.

\section{4) Farmland regulation area}

The conditions are that the overall cultivated land quality in the farmland regulation area is poor, the natural quality of cultivated land is poor, and the hidden danger of ecological security is huge. So it is suggested to strengthen the greening rate of this area and improve the overall ecological environment quality, increase the artificial input in the cultivated land, and increase the construction of water conservancy facilities, and ensure its good irrigation rate. The farmland regulation areas mainly include the low quality area of Grade III and all cultivated land of remaining poor quality areas, which are mainly distributed in the towns such as Kuohongqi Township and Hainuke Township.

\section{CONCLUSION}

The overall result of this study shows that the land management in Cha County is good. According to the natural breakpoint method, it can be divided into 5 quality grades. It can be seen that most of the cultivated land in Cha County is located in the high quality area, which is suitable for the demarcation of basic farmland. Its land is mainly located in north of Cha County, which has the flat terrain and dense river network. It is helpful to improve the spatial regularity of land, reduce the cost of cultivation and improve the production efficiency. The lower quality area and poor quality area are mainly distributed in the middle of Cha County, which has the high terrain and a sparse river network, and is far away from the Yili River and the central urban area of Cha County, and has poor agricultural production conditions. The northern mountains of Cha County are steep and uncultivated. The study also shows that $44.99 \%$ of the cultivated land in Cha County is the priority area, and $26.27 \%$ need to be renovated before being reclassified as basic farmland protection area, and $17.05 \%$ of the cultivated land is the basic farmland reserve area, and $11.68 \%$ of cultivated land needs to be renovated, so as to improve the comprehensive quality of cultivated land and determine the grades of comprehensive quality scores of the cultivated land in Cha County. Finally, the preliminary plan of basic farmland protection area of Cha County is determined according to 4 criterion layer score grades, which can provide a scientific basis for the land management of Cha County.

\section{REFERENCES}

[1] Feng Ting, Zhang Fengrong, Li Can, etc. Spatial Distribution of Basic Farmland in Counties Based on Comprehensive Evaluation of Cultivated Land Quality $[\mathrm{J}]$. Transactions of the Chinese Society of Agricultural Engineering, 2014, 30 (1) : 200-210.

[2] Wu Gaoyang, MiuLijun, etc. Study on Evaluation Method of Cultivated Land Quality Sustainability_Xundian County as An Example of Dynamic Monitoring Pilot of Agricultural Land Quality [J] .Journal of Yunnan Agricultural University, 2014, 29 (6) : 903-910.

[3] Chen Yinjun, Xiao Bilin, Fang Linna, etc. Analysis on Quality of Cultivated Land in China $[\mathrm{J}]$. ScientiaAgriculturaSinica, 2011, 44 (17) : 3557-3564. 
[4] Shen Renfang, Chen Meijun, Kong Xiangbin, etc. Concept, Evaluation and Management Countermeasures of Cultivated Land Quality [J] . ActaPedologicaSinica, 2012, 49 (6) : 1210-1217.

[5] Li Geng, Wu Cifang and Cao Shunai. Study on Delineation of Basic Farmland Index System [ $\mathrm{J}]$. Journal of Agricultural Mechanization Research, 2006 (8) : 46-48. 